Research paper

\title{
Optimisation of fin selection and thermal design of counter-current plate-fin heat exchangers
}

\author{
Kunpeng Guo, Nan Zhang*, Robin Smith \\ Centre for Process Integration, School of Chemical Engineering and Analytical Science, University of Manchester, Manchester M13 9PL, UK
}

\section{H I G H L I G H T S}

- Standardized basic fin geometries are treated as continuous variables.

- Considering thermal hydraulic performance of different fin types in optimisation.

- Fin types and corresponding design parameters are optimised simultaneously.

- The optimisation objective is to minimise the total volume.

- A case study shows a very promising result when compared with a published result.

\section{A R T I C L E I N F O}

Article history:

Received 22 April 2014

Accepted 23 November 2014

Available online 12 December 2014

\section{Keywords:}

Plate-fin heat exchanger

Design

Optimisation

\begin{abstract}
A B S T R A C T
A major challenge in designing optimal multi-stream plate-fin heat exchangers is the large number of combinations of standardised fin geometries for various fin types to choose from, which adds discrete aspects to an already complicated design problem. In this work, a new design algorithm is proposed to address this issue. By treating basic fin geometries such as plate spacing, fin pitch, fin length and fin thickness as continuous variables for all the fin types, different fin types are characterised based on the work published by different researchers. Then by taking into account thermal hydraulic performance of different fin types, optimal fin types and their corresponding design parameters can be obtained simultaneously by minimising the total volume of heat exchanger. The design parameters can be rounded to the nearest standardised fin parts for a feasible design. A case study with a comparison of published results is carried out to demonstrate the effectiveness of the method.
\end{abstract}

๑) 2014 Elsevier Ltd. All rights reserved.

\section{Introduction}

A plate-fin heat exchanger is a type of compact heat exchangers that uses plates and finned chambers to transfer heat between fluids. The main structure of plate-fin heat exchangers, shown in Fig. 1, consists of nozzle (stub pipe), distributor and plate-fin. Typical materials are brazed aluminium, stainless steel and titanium. Fig. 2 presents a typical single chamber made up of plates (parting sheet), fins and side bar (edge seal). Fins are introduced in the design of compact heat exchangers because: A) as a secondary surface, fin can transfer heat to fluid streams through parting sheets; B) due to higher thermal conductivity, heat transfer is more efficient; C) fins can enlarge fluid turbulence and enhance the local convective heat transfer coefficient. Typically, there are four

\footnotetext{
* Corresponding author. Tel.: +44 1613064384; fax: +44 1612367439

E-mail address: nan.zhang@manchester.ac.uk (N. Zhang).
}

categories of fins, namely, plain fin, louvered fin, serrated fin (offset strip fin) and wavy fin (herringbone fin) shown in Fig. 3.

Compared with shell and tube heat exchangers, plate-fin heat exchangers have several distinctive advantages. Firstly, the minimum temperature approach can be as low as $1{ }^{\circ} \mathrm{C}$ in plate-fin heat exchangers, which can contribute to more heat recovery, less utility requirement and operating cost. Secondly, due to higher heat transfer efficient and large surface area per unit volume, a heat exchanger unit can be much smaller and lighter. Furthermore, the possibility of handling several streams in one unit provides the opportunity of reducing the number of heat exchanger [4]. Based on these merits, plate-fin heat exchangers have been extensively used in low temperature process systems, such as cryogenics for separation, LNG plants and ethylene plants, etc [5].

However, there are still several barriers in the application of plate-fin heat exchangers [5]. First of all, fouling limits their application to clean non-fouling streams [6]. Secondly, materials 


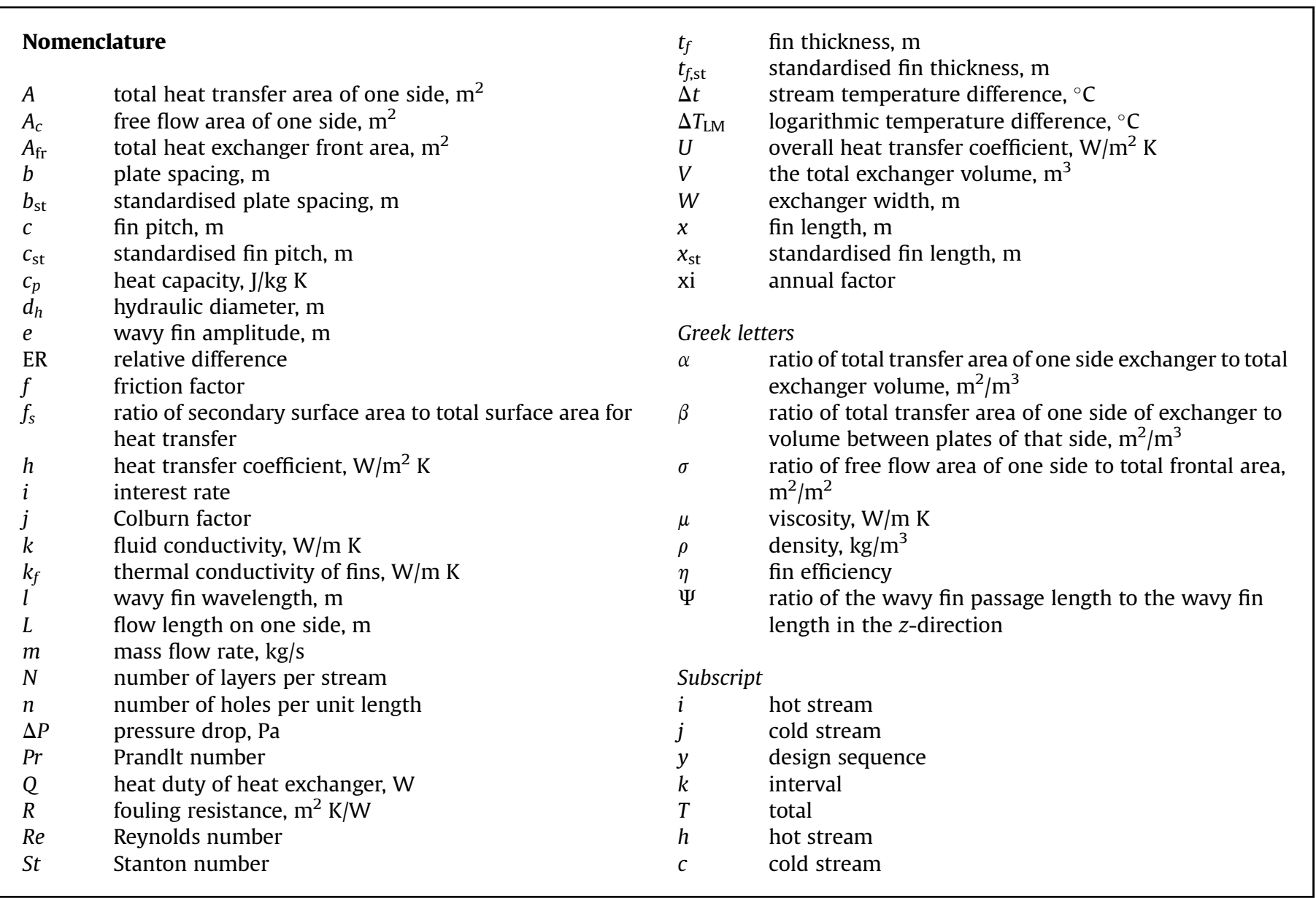

allow the operation condition only at moderate temperature and pressure [7]. Thirdly, the capital cost is another major hurdle [8]. More importantly, there are few general systematic design methods that consider fin selection and thermal design of plate-fin

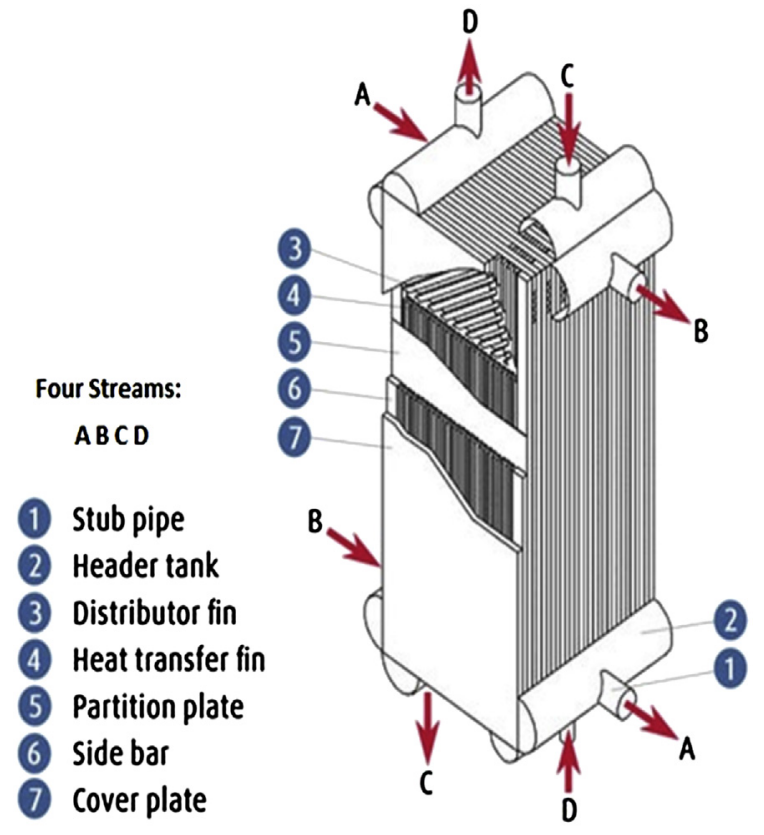

Fig. 1. 4-stream plate-fin heat exchanger [1] heat exchangers simultaneously in the previous researches [9]. Therefore, the objective of this study is to develop a new design methodology and take fin selection and thermal design consideration simultaneously.

Kays and London [13] presented approximately sixty standardised fin parts. Therefore, the large number of discrete combinations of standardised fin parts and types involved in the thermal design is one major difficulty in optimising the design of plate-fin heat exchangers. Pau [4] proposed two new concepts: identicalfin concept and $Z-Y$ graph, which means that the same fins are used for all streams in the early design stage and a $Z-Y$ graph is developed to select fin types. Picon-Nunez et al. [6-9] came up with a new term "Volume Performance Index (VPI)", plotted a

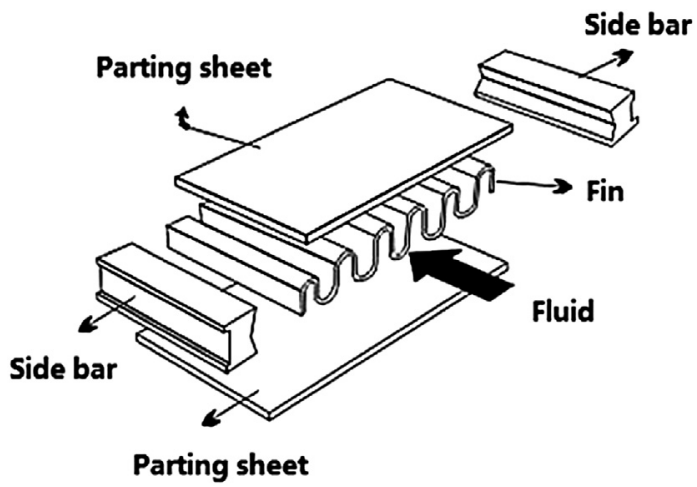

Fig. 2. Plate-fin chamber [2] 

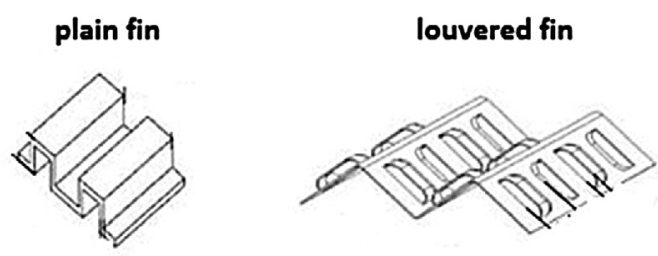

serrated fin (offset strip fin)
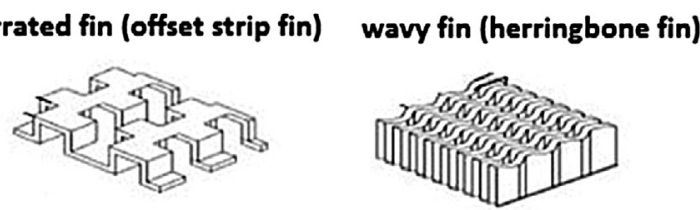

Fig. 3. Typical fin types [3]

graph of VPI vs Reynolds number and conducted sensitivity analysis to select appropriate fins based on assumed Reynolds number. On the basis of the identical fin concept and assumed Reynolds number, fin selection could not provide sophisticated results. On top of that, the optimisation of design is a time-consuming procedure.

Hao et al. developed a new design methodology for a cross-flow plate-fin heat exchanger, taking fin height and fin pitch as variables to minimize the total exchanger weight [10] or annual cost by Genetic Algorithm combined with back propagation neural network [11]. Yousefi [12] optimised cross-flow plate-fin heat exchangers using an $\varepsilon$-NTU model, treating hot flow length, cold flow length, fin height, fin frequency and length, fin thickness and numbers of layers as variables to minimise the total heat transfer area by hybrid Genetic Algorithm with particle swarm solution. He [14] then used a self-adaptive penalty function scheme and employed an improved harmony search algorithm to minimise the total heat transfer area and total pressure drop. Each standardised fin has its corresponding Colburn factor $j$ and friction factor $f$ correlations, which makes the design problem discrete. The optimisation of fin selection cannot converge easily. Therefore, the priority should be given to a general fin selection method, which can select fin types and consider imposed constraints simultaneously.

Current plate-fin heat exchanger design methodologies divide the process streams into several sections or intervals by composite curves and analyse each interval in detail [4]. The main design method is based on a thermal-hydraulic model or a $\varepsilon$-NTU model that present the relationship between heat exchanger volume, heat transfer coefficients and pressure drop.

In general, due to the complex discrete nature of plate-fin heat exchanger design caused by a large number of standardised fin parameters, the design of plate-fin heat exchangers still contains a major element of trial and error, which often leads to sub-optimal design configurations. Therefore, the aim of this study is to develop a systematic design methodology for optimal multi-stream plate-fin heat exchangers that takes into account fin selection and pressure drop utilization simultaneously. A case study from PiconNunez [15] is redesigned and compared to verify the feasibility of the new algorithm.

\section{Problem definition}

Given physical properties and thermal information (mass flow rate, inlet and outlet temperature and pressure) of all process streams, as well as fin physical properties, the objective is to find the optimum design of a plate-fin heat exchanger. Total heat exchanger volume, exchanger dimensions (height, width and length), number of layers per stream, heat transfer coefficients and pressure drop should all be taken into consideration simultaneously.

This design methodology is developed based on the following assumptions:

$>$ Steady-state operation

$>$ Single-phase heat transfer

$>$ Constant fluid physical properties

$>$ Constant heat transfer coefficients

$\triangleright$ Common wall temperature

$\triangleright$ Counter-current arrangement

$>$ Identical fin category

\section{Characterisation of different fin types}

For a two-stream plate-fin heat exchanger, there are approximately 3600 combinations that need to be screened. The number will be increased exponentially with more streams involved. Without an appropriate fin selection method, design would be extremely time-consuming especially for multi-stream plate-fin heat exchangers.

Based on the published data, pressure drop, heat transfer performance and design parameters can be expressed as continuous correlations in this model to convert the discrete design problem to a continuous problem. The Colburn Factor $j$ and the Friction Factor $f$ may be expressed as a function of Reynolds Number and basic fin geometry parameters. Similarly, several characteristic dimensions, hydraulic diameter $d_{h}$, ratio of transfer area to volume of one side $\beta$ and ratio of secondary surface area to total surface area $f_{s}$, may be described as a function of basic fin geometry parameters.

The Colburn Factor $j$ and the Fanning Friction Factor $f$ for offset strip fin cores were regressed by Manglik [16] as a function of Reynolds Number and basic fin geometry, such as, fin pitch $c$, fin height $b$, fin length $x$ and fin thickness $t_{f}$ shown in Fig. 4. Manglik et al. [16] claimed that these correlations predicted the experimental data within $14 \%$, which is much better than that in previous design work.

$$
\begin{aligned}
j= & 0.6522 \operatorname{Re}^{-0.5403}\left(\frac{c}{b}\right)^{-0.1541}\left(\frac{t_{f}}{x}\right)^{0.1499}\left(\frac{t_{f}}{c}\right)^{-0.0678} \\
& \times\left[1+5.269 \times 10^{-5} \operatorname{Re}^{1.34}\left(\frac{c}{b}\right)^{0.504}\left(\frac{t_{f}}{x}\right)^{0.456}\left(\frac{t_{f}}{c}\right)^{-1.055}\right]^{0.1}
\end{aligned}
$$

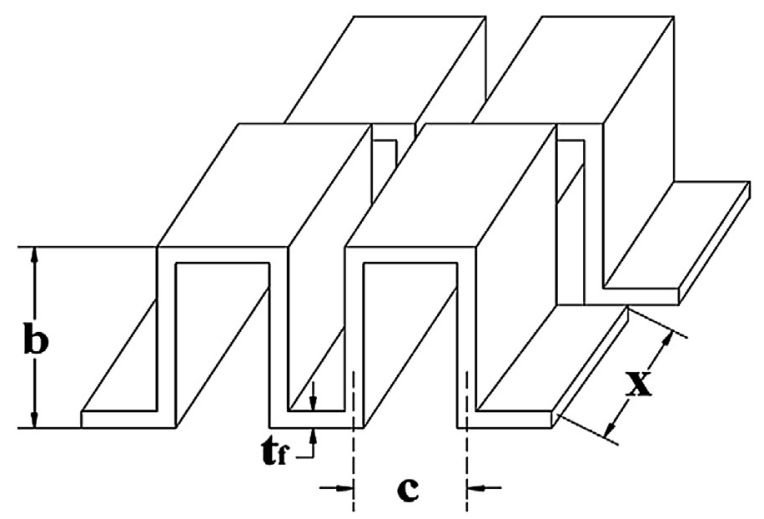

Fig. 4. Basic offset strip fin geometry. 


$$
\begin{aligned}
f= & 9.6243 R e^{-0.7422}\left(\frac{c}{b}\right)^{-0.1856}\left(\frac{t_{f}}{x}\right)^{0.3053}\left(\frac{t_{f}}{c}\right)^{-0.2659} \\
& \times\left[1+7.669 \times 10^{-8} \operatorname{Re}^{4.429}\left(\frac{c}{b}\right)^{0.920}\left(\frac{t_{f}}{x}\right)^{3.767}\left(\frac{t_{f}}{c}\right)^{0.236}\right]^{0.1}
\end{aligned}
$$

$R e$ is the Reynolds Number which is defined as a function of the surface hydraulic diameter:

$\operatorname{Re}=\frac{\dot{m} d_{h}}{\mu A_{c}}$

Equations (1) and (2) are valid for $120<R e<10^{4}, 0.134<c /$ $b<0.997,0.012<t_{f} \mid x<0.048$ and $0.041<t_{f} \mid c<0.121$.

For plain fin, Diani et al. [17] claimed these correlations correctly predicted with a relative deviation of $-0.4 \%$ and absolute deviation of $4.3 \%$ when the Reynolds Number is around 2700 to 10,100 :

$j=0.233 R e^{-0.48}\left(\frac{c}{b}\right)^{0.192}\left(\frac{t_{f}}{b}\right)^{-0.208}$

$f=0.029 R e^{-0.09}\left(\frac{c}{b}\right)^{0.034}\left(\frac{t_{f}}{b}\right)^{-0.169}$

For louver fin, Davenport [18] derived these correlations and agreed with experimental data within $10 \%$ and $12 \%$ respectively when the Reynolds Number is around 300 to 4000 :

$j=0.249 R e^{-0.42} b^{0.26}\left(\frac{x}{b}\right)^{1.1} x^{0.33}$

$f=0.494 R e^{-0.39} c^{0.46}\left(\frac{x}{c}\right)^{1.1}\left(\frac{b}{c}\right)^{0.33}$

For wavy fin, Dong [19] verified that the mean deviations of these correlations in the range of the Reynolds Number between 800 and 6500 for $j$ and $f$ factors were $4.4 \%$ and $5.1 \%$ respectively:

$j=0.0836 R e^{-0.2309}\left(\frac{c}{b}\right)^{0.1284}\left(\frac{x}{l}\right)^{-0.326}\left(\frac{c}{2 e}\right)^{-0.153}$

$f=1.16 R e^{-0.309}\left(\frac{c}{b}\right)^{0.3703}\left(\frac{x}{l}\right)^{-0.1152}\left(\frac{c}{2 e}\right)^{-0.25}$

To make the model continuous, for each category of fins, hydraulic diameter $d_{h}$, secondary surface ratio $f_{s}$ and heat transfer surface area per unit volume $\beta$ may be simply regressed as a function of basic fin geometry parameters. The continuous correlations for four fin categories are listed as below:

For offset strip-fin [20]:

$\beta=\frac{2\left(b-t_{f}\right) x+2\left(c-t_{f}\right) x+2\left(b-t_{f}\right) t_{f}+c t_{f}}{b c x}$

$f_{s}=\frac{2\left(b-t_{f}\right) x+2\left(b-2 t_{f}\right) t_{f}+c t_{f}}{2\left(b-t_{f}\right) x+2\left(c-t_{f}\right) x+2\left(b-t_{f}\right) t_{f}+c t_{f}}$

$$
d_{h}=\frac{4\left(c-t_{f}\right)\left(b-t_{f}\right) x}{2\left(\left(c-t_{f}\right) x+\left(b-t_{f}\right) x+t_{f}\left(b-t_{f}\right)\right)+t_{f}\left(c-t_{f}\right)-t_{f}^{2}}
$$

For plain fin [21]:

$\beta=\frac{2(b+c)}{b c}$

$f_{s}=\frac{2 b+5 c / 3}{2 b+4 c}$

$d_{h}=\frac{2 b\left(c-t_{f}\right)}{b+c}$

For louvered fin [20]:

$\beta=\frac{2 x\left(c-t_{f}\right)+2 b c+2\left(\sqrt{c^{2}+b^{2}}-t_{f}\right)}{b c}$

$f_{s}=\frac{2\left(\sqrt{c^{2}+b^{2}}-t_{f}\right)}{2 x\left(c-t_{f}\right)+2 b c+2\left(\sqrt{c^{2}+b^{2}}-t_{f}\right)}$

$d_{h}=\frac{4 b c-t_{f}\left(\sqrt{c^{2}+b^{2}}-t_{f}\right)}{2 x\left(c-t_{f}\right)+2 b c+2\left(\sqrt{c^{2}+b^{2}}-t_{f}\right)}$

For wavy fin [21]:

$\beta=\frac{2 \Psi b+2 c}{b c}$

$f_{s}=\frac{2 \Psi b+c}{2 \Psi b+2 c}$

$d_{h}=\frac{2 b c}{b+\Psi_{c}}$

\section{Modelling of thermal-hydraulic performance of plate-fin heat exchangers}

The thermal-hydraulic model is based on the basic heat transfer design equation for a two-stream heat exchanger [6-9,20].

$Q=U A \Delta T_{\mathrm{LM}}$

With the inclusion of surface fouling and fin effects, the overall heat transfer coefficient is defined as below [20]:

$\frac{1}{U A}=\frac{1}{U_{1} A_{1}}=\frac{1}{U_{2} A_{2}}=\frac{1}{\eta_{1} A_{1}}\left(\frac{1}{h_{1}}+R_{1}\right)+\frac{1}{\eta_{2} A_{2}}\left(\frac{1}{h_{2}}+R_{2}\right)+R_{w}$

Combining it with the basic equation gives

$A_{1}=\frac{Q}{\Delta T_{\mathrm{LM}}}\left[\frac{1}{\eta_{1}}\left(\frac{1}{h_{1}}+R_{1}\right)+\frac{1}{\eta_{2}}\left(\frac{A_{1}}{h_{2} A_{2}}+R_{2}\right)+R_{w}\right]$

where $A_{1}$ and $A_{2}$ represent the total heat transfer area of each side; $h_{1}$ and $h_{2}$ are the film heat transfer coefficients of each side; $R_{1}$ and $R_{2}$ are the thermal resistance due to fouling in each side. $R_{w}$ is the wall thermal resistance. 
Due to different fin types and densities for both streams, the heat exchanger volume will be more reasonable as the key indicator of sizing than heat transfer area in plate-fin heat exchanger design [13]. Kays and London [13] set a new parameter $\alpha$ that relates the total heat transfer area of one side of heat exchanger to the total heat exchanger volume. Based on the definition, the total heat transfer area of one side can be expressed as:

$A_{1}=\alpha_{1} V_{T}$

$A_{2}=\alpha_{2} V_{T}$

where $\alpha$ can be calculated by the heat exchanger geometry [13]:

$\alpha_{1}=\beta_{1}\left(\frac{b_{1}}{b_{1}+b_{2}}\right)$

$\alpha_{2}=\beta_{2}\left(\frac{b_{2}}{b_{1}+b_{2}}\right)$

where $\beta$ is the ratio of total heat transfer area of one side to the volume between plates of that side and $b$ is the plate spacing of each side respectively.

Therefore, by substituting Equations (25) and (26) into Equation (24), the heat exchanger volume expressed as [13]:

$V_{T}=\frac{Q}{\Delta T_{\mathrm{LM}}}\left[\frac{1}{\eta_{1} \alpha_{1}}\left(\frac{1}{h_{1}}+R_{1}\right)+\frac{1}{\eta_{2} \alpha_{2}}\left(\frac{1}{h_{2}}+R_{2}\right)\right]$

The overall surface efficiency $\eta_{1}$ and $\eta_{2}$ can be calculated by Ref. [13]:

$\eta=1+f_{s}\left\{\frac{\tanh \left[\left(\frac{2 h}{k_{f} t_{f}}\right)^{1 / 2} \frac{b}{2}\right]}{\left[\left(\frac{2 h}{k_{f} t_{f}}\right)^{1 / 2} \frac{b}{2}\right]}-1\right\}$

where $k_{f}$ is the thermal conductivity of fin; $t_{f}$ is the fin thickness.

The heat transfer performance is presented as the Colburn factor $j[20]$,

$j=S t \operatorname{Pr}^{2 / 3}$

where Pr is the Prandlt Number, St is the Stanton Number which are given by Ref. [20]:

$S t=\frac{h A_{c}}{\dot{m} C_{p}}$

$\operatorname{Pr}=\frac{\mu C_{p}}{k}$

Therefore, the heat transfer coefficient can be rearranged as [6]:

$h=\frac{\dot{m} C_{p} j}{A_{c} \operatorname{Pr}^{2 / 3}}$

A similar procedure can be applied to express the pressure drop. The pressure drop across the core of a heat exchanger is [13]:

$\Delta P=\frac{2 f L \dot{m}^{2}}{\rho d_{h} A_{c}^{2}}$

\section{Methodology for optimal fin selection}

Based on the above models for different fin categories and the thermal-hydraulic model, the discrete design problem can be converted to a continuous NLP problem. Since Friction Factor, Colburn Factor and design parameters $\left(d_{h}, f_{s}, \beta\right)$ can be expressed as a function of Reynolds Number Re and basic fin geometries, plate spacing $b$, fin pitch $c$, fin thickness $t_{f}$ and fin length $x$ are taken as continuous design variables in this methodology. The objective function, total exchanger volume can be minimised by the CONOPT solver in GAMS to find the optimum fin types.

By combining these two models together, heat transfer coefficient and pressure drop can also be related to basic geometry parameters. Therefore, fin selection can be carried out with consideration of imposed constraints, such as pressure drop and fluid flow types. In other words, there is no need to select the fin type blindly based on assumed Reynolds Number and regardless of pressure drop in the early design stage.

Due to standardised fin parts, the optimum fin geometry may not exist. Compared with fixed standardised fin geometries, the "relative difference" ER should be calculated to select the closet fin types. A smaller ER value indicates a better match.

$\mathrm{ER}=\left|\frac{b-b_{\mathrm{st}}}{b_{\mathrm{st}}}\right|+\left|\frac{c-c_{\mathrm{st}}}{c_{\mathrm{st}}}\right|+\left|\frac{x-x_{\mathrm{st}}}{x_{\mathrm{st}}}\right|+\left|\frac{t_{f}-t_{f, \mathrm{st}}}{t_{f, \mathrm{st}}}\right|$

\section{Overall design methodology of plate-fin heat exchangers}

The whole general plate-fin heat exchanger design methodology is presented in Fig. 2.

Pinch technology [22] is employed to represent process streams directly in a graphical format. The composite curves include hot and cold composite curves, which depict the heat balance of process streams and give the minimum hot and cold utility requirements. Based on assumed constant fluid physical properties, the composite curve is formed by several straight lines. The kink points indicate certain process streams inlet or outlet points. Therefore, the composite curves can be divided into several enthalpy intervals by kink points shown in Fig. 3 [4-9].

With the interval decomposition, the flow rate, permissible pressure drop and heat load per stream are fixed in each enthalpy interval. The allowable pressure drop per stream in each interval is distributed linearly according to the fraction of heat load [6].

$\Delta P_{i, k}=\Delta P_{i, \text { total }}\left(\frac{\Delta H_{i, k}}{\Delta H_{i, \text { total }}}\right)$

where $i$ is the stream number, $k$ is the interval number.

In each interval, the entry and exit temperatures are fixed. The temperature driving force is uniform for all hot streams and cold streams. Therefore, each hot stream can match any cold stream in the same interval.

In this work, a superstructure based heat exchanger network is employed at the design stage. Each hot stream is spilt into several streams to match every cold stream. Conversely, each cold stream is spilt to allow a match with all the hot streams. Fig. 6 illustrates a simple superstructure example (Fig. 7).

The heat load distribution is calculated by.

$Q_{i, j, k}=Q_{i, k} \times \frac{Q_{j, k}}{\sum_{j} Q_{j, k}}$ 


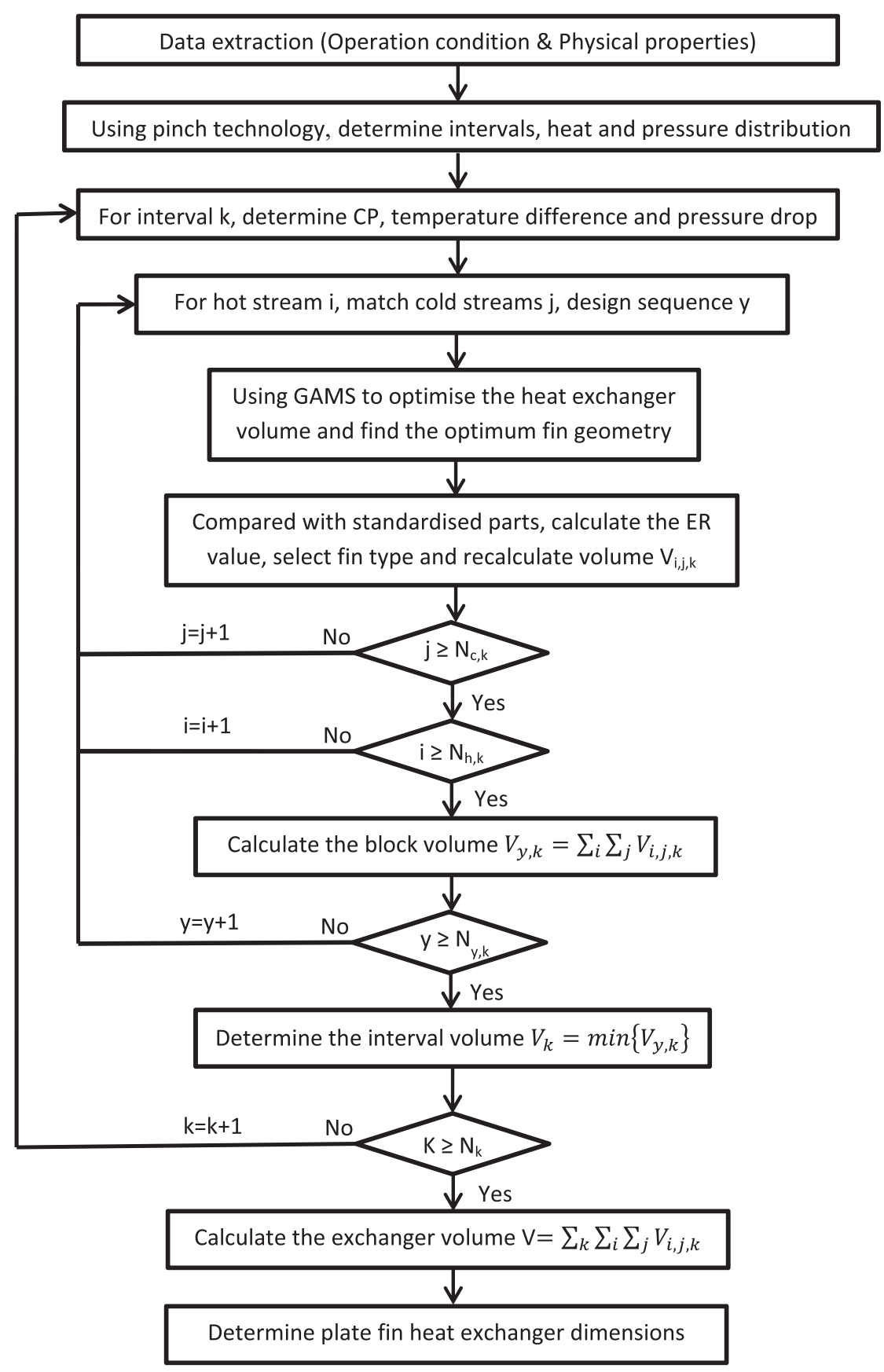

Fig. 5. Overall optimum design algorithm.

Every match can be regarded as a two-stream plate-fin heat exchanger with a volume $V_{i, j, k}$. Each interval is a plate-fin heat exchanger network. Consequently, the volume of each interval is the sum of each match included. The whole plate-fin heat exchanger volume is the sum of volume of all intervals involved.

$V_{k}=\sum_{i} \sum_{j} V_{i, j, k}$

$V=\sum_{k} V_{k}=\sum_{k} \sum_{i} \sum_{j} V_{i, j, k}$

As mentioned above, each interval is a two-stream heat exchanger network. At the design stage, once a match is set and optimised, the fin types for these two streams will be determined to ensure the unified pressure drop for the same stream in the same interval. Therefore, different design sequences will give different heat exchanger volumes. Fin types are determined based on the minimum interval volume.

Based on selected fin types, the heat exchanger volume should be recalculated and used to determine the interval and exchanger dimensions (width $W$, length $L$ and height $H$ ) and number of layers per stream.

The frontal area $A_{\mathrm{fr}}$ can be obtained by free flow area $A_{c}$ [13]:

$$
\sigma=\frac{A_{c}}{A_{\mathrm{fr}}}=\frac{\alpha d_{h}}{4}
$$


Hot and Cold Composite Curves

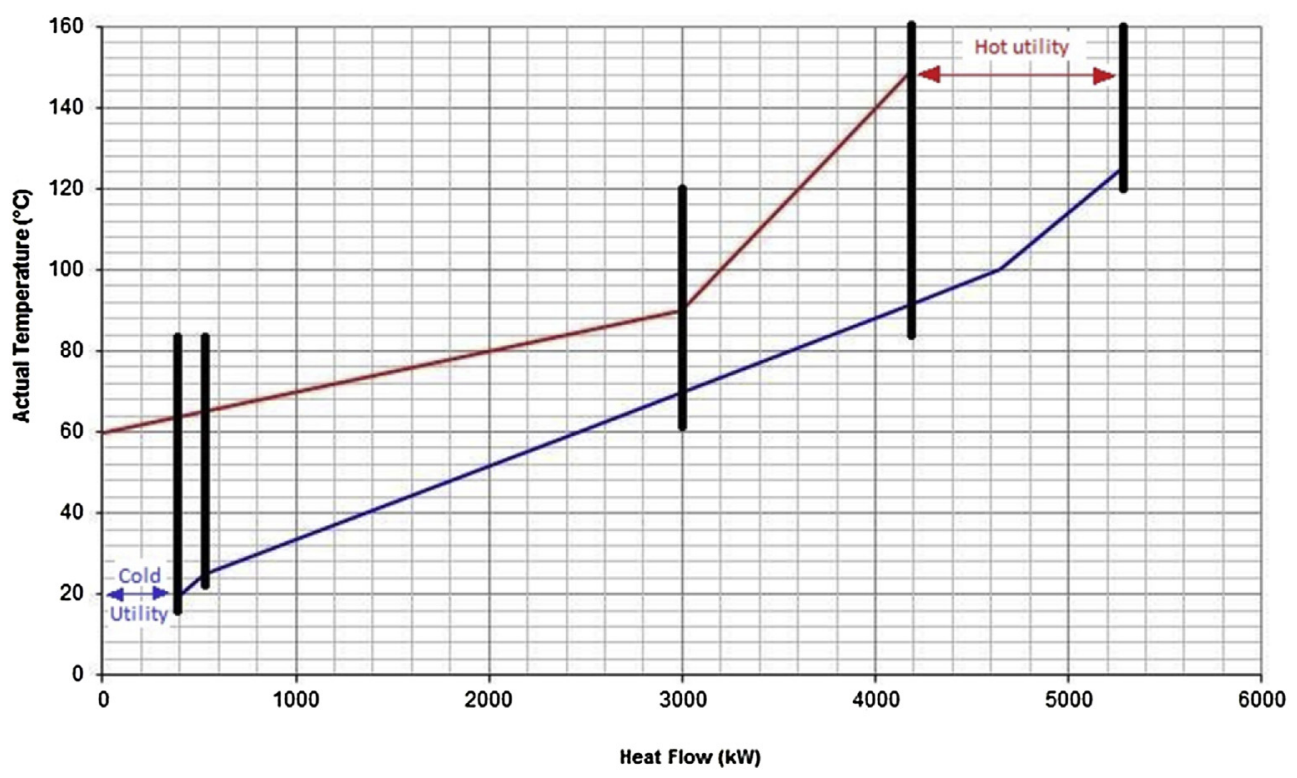

Fig. 6. Composite curves and interval decomposition.

The length $L$ can be determined by Ref. [13]:

$L=\frac{V_{T}}{A_{\mathrm{fr}}}$

With the assumed width $\mathrm{W}$, the height of exchanger $\mathrm{H}$ and the number of layers per stream can be deduced by Ref. [13]:

$H=\frac{A_{\mathrm{fr}}}{W}$

$N=\frac{A_{\mathrm{fr}}}{W\left(b_{1}+b_{2}\right)}$

\section{Case study}

A four-stream plate-fin heat exchanger [8] is revisited in this work. The process stream information is listed below in Table 1. To test and verify the feasibility of the new design methodology, the

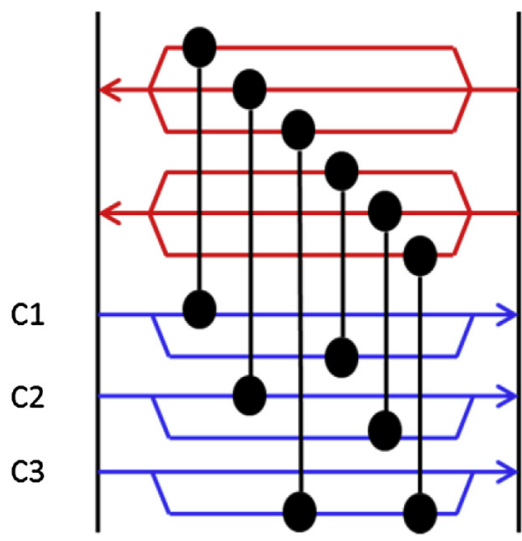

$\mathrm{H} 1$

$\mathrm{H} 2$ minimum temperature approach of $20^{\circ} \mathrm{C}$ is assumed the same as in the previous work [8].

Fig. 5 presents the hot and cold composite curves and shows the interval decomposition in this case. The detailed information of each interval is shown in Table 2. The distribution of pressure drop per stream is listed in Table 3.

The optimisation is executed with GAMS version 23.4 on a $2.6 \mathrm{GHz}$ 4th Intel Core i5 PC with $8 \mathrm{~GB}$ memory. The CONPT solver is used in this study and the computation time is $10-15 \mathrm{~s}$. There are 9 variables and 8 nonlinear equations in the optimisation program.

\subsection{Heat exchanger volume and fin selection}

The use of identical fin categories is assumed in this case study. With higher heat transfer efficiency and larger pressure drop, offset strip fin and louvered fin cannot meet the heat exchanger requirement because of unrealistic heat exchanger size and pressure drop. Therefore, the plain fin is employed in this case in spite of lowest heat transfer efficiency. Take interval $1 / \mathrm{H} 1-\mathrm{C} 1$ match as an example, the optimum fin height, fin thickness and fin pitch for $\mathrm{H} 1$ side obtained from GAMS are $6.05 \mathrm{~mm}, 1.20 \mathrm{~mm}$ and $0.152 \mathrm{~mm}$ respectively. By calculating ER value, the most similar fin type is plain-fin 19.86. The optimum fin height, fin thickness and fin pitch for $\mathrm{C} 1$ side are $6.45 \mathrm{~mm}, 1.24 \mathrm{~mm}$ and $0.152 \mathrm{~mm}$ respectively. Among all standardised parts sizes, plain-fin 19.86 (fin height $6.35 \mathrm{~mm}$, fin pitch $1.278 \mathrm{~mm}$, fin thickness $0.152 \mathrm{~mm}$ ) is the best choice for $\mathrm{C} 1$ side. The same method is employed in each match and interval. To determine the interval dimensions, the width in this

Table 1

Process data for case study [8]

\begin{tabular}{lrrrlllll}
\hline Stream & $T_{S}\left({ }^{\circ} \mathrm{C}\right)$ & $T_{t}\left({ }^{\circ} \mathrm{C}\right)$ & $\begin{array}{l}\text { Flow rate } \\
(\mathrm{kg} / \mathrm{s})\end{array}$ & $\begin{array}{l}\Delta P \\
(\mathrm{KPa})\end{array}$ & $\begin{array}{l}\rho \\
\left(\mathrm{kg} / \mathrm{m}^{3}\right)\end{array}$ & $\begin{array}{l}C_{p} \\
\left(\mathrm{~J} / \mathrm{kg}{ }^{\circ} \mathrm{C}\right)\end{array}$ & $\mu(\mathrm{cP})$ & $\begin{array}{l}K \\
\left(\mathrm{~W} / \mathrm{m}{ }^{\circ} \mathrm{C}\right)\end{array}$ \\
\hline $\mathrm{H} 1$ & 150 & 60 & 25.0 & 46 & 700 & 800 & 0.3 & 0.12 \\
$\mathrm{H} 2$ & 90 & 60 & 106.7 & 60 & 700 & 750 & 0.4 & 0.12 \\
$\mathrm{C} 1$ & 20 & 125 & 27.7 & 30 & 750 & 900 & 0.5 & 0.12 \\
$\mathrm{C} 2$ & 25 & 100 & 37.5 & 86 & 750 & 800 & 0.5 & 0.12 \\
\hline
\end{tabular}

Fig. 7. Interval superstructure. 
Table 2

Interval decomposition results.

\begin{tabular}{lclllll}
\hline Interval & $T_{H, \text { in }}\left({ }^{\circ} \mathrm{C}\right)$ & $T_{H, \text { out }}\left({ }^{\circ} \mathrm{C}\right)$ & $T_{C \text {,in }}\left({ }^{\circ} \mathrm{C}\right)$ & $T_{C \text {,out }}\left({ }^{\circ} \mathrm{C}\right)$ & $\Delta T_{\mathrm{LM}}\left({ }^{\circ} \mathrm{C}\right)$ & $\Delta H(\mathrm{~kW})$ \\
\hline 1 & 65.3 & 64 & 20 & 25 & 42.13 & 124.65 \\
2 & 90 & 65.3 & 25 & 70 & 29.00 & 2417.8 \\
3 & 150 & 90 & 70 & 91.8 & 35.74 & 1200.0 \\
\hline
\end{tabular}

Table 3

Pressure drop distribution.

\begin{tabular}{llll}
\hline Stream & \multicolumn{2}{l}{$\Delta P$ distribution $(\mathrm{kPa})$} & \\
\cline { 2 - 4 } & Interval 1 & Interval 2 & Interval 3 \\
\hline H1 & 0.72 & 12.62 & 30.66 \\
H2 & 2.60 & 49.40 & - \\
C1 & 1.43 & 12.86 & 6.23 \\
C2 & - & 51.60 & 25.00 \\
\hline
\end{tabular}

case is assumed to be $0.75 \mathrm{~m}$ as the basic design. The detailed design information is shown below in Tables 4-6.

From Tables 4-6, fin types employed (plain fin 15.08 and plain fin $11.94 \mathrm{~T}$ ) in the basic design cannot provide the minimum heat exchanger volume. Because the fin type selection in the basic design is based on the graph of VPI (Volume Performance Index) vs assumed Reynolds Number Re. Once the Reynolds Number is calculated, the fin type will be reselected. The iteration will not stop until the final Reynolds Number agrees well with the previous Reynolds Number within the accepted limit. But in the new methodology, the fin selection and thermal design are optimised simultaneously, to avoid random selection and improve the precision. Using plain-fin 19.86 saves the block volume by almost $16.7 \%$, $1 \%$ and $37.6 \%$ respectively. The number of layers in each block is changed in different directions correspondingly. Through the verification of this case study, the fin selection can be completed while designing the plate-fin heat exchanger, rather than drawing a graph of special terms vs Reynolds Number and selecting fin types based on assumed Reynolds Number at early design stage. The fin selection problem can be taken as a continuous problem through the integration of continuous expression of fin parameters in spite of dealing with standardised parts. Moreover, the new design methodology not only provides a better design, but also improves the job efficiency, especially for multi-stream plate-fin heat exchanger design.

\subsection{Pressure drop sensitivity analysis}

Pressure drop is an important constraint, which should be considered in the plate fin heat exchanger design process. In the new design methodology, the allowed pressure drop of a critical stream is maximised or fully utilised, while pressure drop values for other streams are calculated consequently. But all pressure drops should be less than allowed maximum pressure drops.

Table 7 lists the allowed maximum pressure drops, pressure drop of each stream in each interval in the basic case and the new design. The total pressure drop for each stream is also listed in Table 8.

Table 4

Interval 1 design details.

\begin{tabular}{|c|c|c|c|c|c|c|c|c|c|c|}
\hline \multirow[t]{2}{*}{ Interval 1} & \multicolumn{4}{|c|}{ Interval dimensions } & \multicolumn{3}{|l|}{ Fin types } & \multicolumn{3}{|c|}{ Number of layers } \\
\hline & Volume $\left(\mathrm{m}^{3}\right)$ & Length (m) & Width (m) & Height (m) & $\mathrm{H} 1$ & $\mathrm{H} 2$ & $\mathrm{C} 1$ & $\mathrm{H} 1$ & $\mathrm{H} 2$ & $\mathrm{C} 1$ \\
\hline Basic Case & 0.012 & 0.053 & 0.750 & 0.313 & PF15.08 & PF11.94T & PF15.08 & 4.9 & 19.7 & 24.6 \\
\hline New Design & 0.010 & 0.170 & 0.750 & 0.715 & PF19.86 & PF19.86 & PF19.86 & 1.2 & 4.7 & 5.9 \\
\hline
\end{tabular}

${ }^{*} \mathrm{PF}-$ plate fin.

Table 5

Interval 2 design details.

\begin{tabular}{|c|c|c|c|c|c|c|c|c|c|c|c|c|}
\hline \multirow[t]{2}{*}{ Interval 2} & \multicolumn{4}{|c|}{ Interval dimensions } & \multicolumn{4}{|l|}{ Fin types } & \multicolumn{4}{|c|}{ Number of layers } \\
\hline & Volume $\left(\mathrm{m}^{3}\right)$ & Length (m) & Width (m) & Height (m) & $\mathrm{H} 1$ & $\mathrm{H} 2$ & $\mathrm{C} 1$ & $\mathrm{C} 2$ & $\mathrm{H} 1$ & $\mathrm{H} 2$ & $\mathrm{C} 1$ & $\mathrm{C} 2$ \\
\hline Basic Case & 0.204 & 0.868 & 0.750 & 0.313 & PF15.08 & PF15.08 & PF15.08 & PF15.08 & 9.0 & 36.2 & 20.5 & 24.7 \\
\hline New Design & 0.204 & 1.008 & 0.750 & 0.272 & PF19.86 & PF19.86 & PF19.86 & PF19.86 & 4.5 & 16.8 & 9.7 & 11.6 \\
\hline
\end{tabular}

Table 6

Interval 3 design details.

\begin{tabular}{|c|c|c|c|c|c|c|c|c|c|c|}
\hline \multirow[t]{2}{*}{ Interval 3} & \multicolumn{4}{|c|}{ Interval dimensions } & \multicolumn{3}{|l|}{ Fin types } & \multicolumn{3}{|c|}{ Number of layers } \\
\hline & Volume $\left(\mathrm{m}^{3}\right)$ & Length (m) & Width (m) & Height (m) & $\mathrm{H} 1$ & $\mathrm{C} 1$ & $\mathrm{C} 2$ & $\mathrm{H} 1$ & $\mathrm{C} 1$ & $\mathrm{C} 2$ \\
\hline Basic Case & 0.178 & 0.780 & 0.750 & 0.313 & PF15.08 & PF15.08 & PF15.08 & 20.4 & 9.2 & 11.1 \\
\hline New Design & 0.111 & 0.530 & 0.750 & 0.282 & PF19.86 & PF19.86 & PF19.86 & 22.2 & 10 & 12.2 \\
\hline
\end{tabular}

Table 7

Pressure drop details in each interval.

\begin{tabular}{|c|c|c|c|c|c|c|c|c|c|c|}
\hline & \multicolumn{3}{|c|}{ Interval 1} & \multicolumn{4}{|c|}{ Interval 2} & \multicolumn{3}{|c|}{ Interval 3} \\
\hline & $\mathrm{H} 1$ & $\mathrm{H} 2$ & $\mathrm{C} 1$ & H1 & $\mathrm{H} 2$ & $\mathrm{C} 1$ & $\mathrm{C} 2$ & $\mathrm{H} 1$ & $\mathrm{C} 1$ & $\mathrm{C} 2$ \\
\hline Allowed & 0.72 & 2.60 & 1.43 & 12.62 & 49.40 & 12.86 & 51.60 & 30.66 & 6.23 & 25.00 \\
\hline Basic Case & 0.243 & 0.48 & 0.17 & 7.52 & 9.83 & 12.92 & 15.77 & 0.481 & 7.4 & 13.82 \\
\hline New Design & 0.46 & 0.91 & 0.322 & 9.22 & 10.07 & 12.70 & 16.12 & 1.15 & 6.23 & 7.81 \\
\hline
\end{tabular}

${ }^{*}$ All pressure drops are in $\mathrm{kPa}$. 
Table 8

Comparison of total pressure drop.

\begin{tabular}{llcl}
\hline Stream & Allowed & Basic case & New design \\
\hline H1 & 44 & 8.25 & 10.83 \\
H2 & 52 & 10.31 & 10.98 \\
C1 & 20.52 & 20.49 & 19.25 \\
C2 & 76.6 & 29.59 & 23.93 \\
\hline
\end{tabular}

*All pressure drops are in $\mathrm{kPa}$.

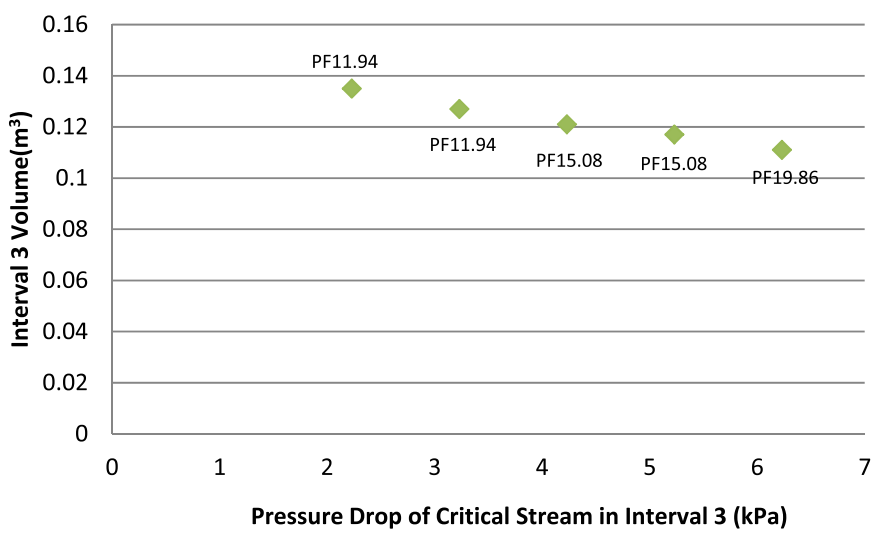

Fig. 8. Pressure drop sensitive analysis.

Compared with plain fin 15.08 , plain fin 19.86 provides a smaller heat exchanger but generates higher pressure drop. Actually, a fin type has an effect on the rate of heat transfer and pressure drop utilization. Higher fin density gives a larger heat transfer area, which can enhance heat transfer efficiency and decrease heat exchanger size, but consequently increases the pressure drop. In the optimal design, not only pressure drop of a critical stream is maximised, but also the pressure drop of other streams should be under the allowed pressure drops.

In the existing method, provided that the total pressure drop is under the allowed value, small tolerance in any interval can be accepted. Based on assumed Reynolds numbers, the previous methodology needs iteration to converge after obtaining real Reynolds numbers in the initial design. Therefore, the verified pressure drop could violate the allowed maximum pressure drop in some cases, as shown in Table 7. On the other hand, the new design methodology considers fin selection and pressure drop simultaneously that can avoid any pressure drop violation.

To investigate the influence of pressure drop on fin selection, a sensitive analysis is studied by changing the allowed pressure drop of the critical stream $\mathrm{C} 1$ in the interval 3 and keeping other pressure drops constant. The fin selection results and corresponding heat exchanger volumes are shown in Fig. 8.

The higher density fin type gives higher heat transfer coefficient and pressure drop. Clearly, when the allowed pressure drop of the critical stream increases, higher density fin types can be employed for a smaller heat exchanger volume. Hence, there is a trade-off between pressure drop and heat exchanger volume. Therefore, fin selection and pressure drop optimisation for every single stream should be considered simultaneously.

\section{Conclusions}

A new design methodology for multi-stream plate-fin heat exchangers is proposed to minimise heat exchanger volume. The selection of fin types and imposed constraints can be considered simultaneously in the optimal design process by regressing Friction Factor $f$, Colburn Factor $j$ and some design parameters $\left(d_{h}, f_{s}, \beta\right)$ as a function of basic fin geometries such as fin height $b$, fin pitch $c$, fin length $x$ and fin thickness. The discontinuous optimisation problem caused by discrete standardised fin types can be converted to a continuous problem to overcome computation difficulties. For a large scale multi-stream plate-fin heat exchanger, the design quality could be greatly improved.

However, this design methodology is developed based on assumed constant fluid physical properties and identical fin category for both sides. In practical, especially in low temperature systems, various physical properties, induced by phase and/or temperature change, should be taken into consideration in the design methodology as well as mixing and matching fin categories in the plate-fin heat exchanger. Further research work is needed to tackle these challenges.

\section{References}

[1] Linde Engineering, Aluminium Plate-fin Heat Exchangers (image online), 2013. Available from: http://www.linde-engineering.com/internet.global. lindeengineering.global/en (accessed 05.03.13).

[2] Bestinnovativesource.com, Plate Fin Heat Exchangers, (image online) 2013 Available from: http://www.bestinnovativesource.com/2013/05/23/plate-finheat-exchanger/(accessed 08.07.13).

[3] Thermopedia.com, Plate Fin Heat Exchangers, (image online) 2013, Available from: http://www.thermopedia.com/content/1036/(accessed 14.03.13).

[4] L.M. Pua, X.X. Zhu, Integrated heat exchanger network and equipment design using compact heat exchangers, Heat Transfer Eng. 23 (6) (2002) 18-35.

[5] L.M. Pua, X.X. Zhu, Overall Optimisation Framework for Multi-stream Plate-fin Heat Exchanger Network Synthesis (Ph.D. thesis), The University of Manchester, 1999.

[6] M. Picon-Nunez, G.T. Polley, M. Medina-Flores, Thermal design of multistream plate-fin heat exchangers, Appl. Therm. Eng. 22 (2002) 1643-1660.

[7] M. Picon-Nunez, E. Torres-Reyes, A. Gallegos-Munoz, Surface selection and design of plate-fin heat exchangers, Appl. Therm. Eng. 19 (1999) 917-931.

[8] M. Picon-Nunez, L. Robles, Flow passage arrangement and surface selection in multi-stream plate-fin heat exchangers, Heat Transfer Eng. 26 (2005) 5-14.

[9] G.T. Polley, M. Picon-Nunez, Methodology for the design of multi-stream plate-fin heat exchangers, in: B. Suden, P.J. Heggs (Eds.), Recent Advances in Analysis of Heat Transfer for Fin Type Surface, WIT Press, Ashurst, Southampton, 2000, pp. 251-276.

[10] H. Peng, X. Ling, Optimal design approach for the plate-fin heat exchangers using neural networks cooperated with genetic algorithms, Appl. Therm. Eng. 28 (2008) 642-650.

[11] Hao Peng, X. Ling, E. Wu, An improved particle swarm algorithm for optimal design of plate-fin heat exchangers, Ind. Eng. Chem. Res. 49 (2010) 6144-6149.

[12] M. Yousefi, R. Enayatifar, A.N. Darus, Optimal design of plate-fin heat exchangers by a hybrid evolutionary algorithm, Int. Commun. Heat Mass Transfer 39 (2012) 258-263.

[13] W.M. Kays, A.L. London, Compact Heat Exchangers, McGraw-Hill Book Co, New York, 1984.

[14] M. Yousefi, R. Enayatifar, A.N. Darus, A.H. Abdullah, Optimization of plate-fin heat exchangers by an improved harmony search algorithm, Appl. Therm. Eng. 50 (2013) 877-885.

[15] M. Picon-Nunez, Development of Compact and Multi-stream Exchangers Design Methodology for Use in Integrated Plant (PhD thesis), The University of Manchester, 1995.

[16] R.M. Manglik, A.E. Bergles, Heat transfer and pressure drop correlations for the rectangular offset strip fin compact heat exchanger, Exp. Therm. Fluid Sci. 10 (1995) 171-180.

[17] A. Diani, S. Mancin, L. Rossetto, Exp. Numer. Anal. Differ. Ext. Surf. 395 (1) (2012) 012045.

[18] C.J. Davenport, Correlation for heat transfer and flow friction characteristics of louver fin, AIChE Symp. 225 (79) (1983) 19-27.

[19] J.Q. Dong, J.P. Chen, Z.J. Chen, Y.M. Zhou, W.F. Zhang, Heat transfer and pressure drop correlations for the wavy fin and flat tube heat exchangers, Appl. Therm. Eng. 27 (2007) 2066-2073.

[20] R.K. Shah, P. Dusan, D.P. Sekulic, Fundamental of Heat Exchanger Design, John Wiely \& Sons, New York, 2003.

[21] Y.H. Zhu, Y.Z. Li, Three-dimensional numerical simulation on the laminar flow and heat transfer in four basic fins of plate-fin heat exchangers, J. Heat Transfer 130 (2008) 111801.

[22] B. Linnhoff, D.W. Townsend, D. Boland, G.F. Hewitt, B.E.A. Thomas, A.R. Guy, et al., A User Guide on Process Integration for the Efficient Use of Energy, IChemE, Rugby, UK, 1994. 